\title{
Hypothermia in Organophosphate Compound Poisoning: Recognizing the Big Chill
}

Sir,

Munta et al. ${ }^{[1]}$ have highlighted the clinical importance of hypothermia in organophosphate compound (OPC) poisoning. At this juncture, we would like to share some of our experiences and applied aspects of hypothermia. ${ }^{[2]}$ The factors that contributed for the occurrence of hypothermia in OPC poisoning of our series were the nature of the compound (Class I OPC compounds more than Class II or III) ${ }^{[3]}$ and the quantity consumed; pharmacokinetics and dynamics of OPC as influenced by extremes of ages, co-ingestion of alcohol, and deficiency of pseudocholinesterase ${ }^{[4]}$ (observed among Arya Vaishya community of our area); and the stimulation of muscarinic cholinergic pathways mediated by the OPC leading to profuse sweating and peripheral vasodilation.

Many such cases required longer stay in intensive care unit and tracheostomy and had turbulent clinical course. The lessons learned after handling OPC poisoning with hypothermia were - assessment of the cases for hypothermia and if so, re-elicit clinical history for the nature and quantity of the OPC consumed, co-ingestion of alcohol, delayed arrival, and other contributory factors; evaluation of the cases for adverse clinical course/complications, an interaction with health-care team for appropriate care, documentation of the details, and enlightening the caregivers on the details and outcome so as to avoid conflicts.

Accordingly, the health-care team shall be sensitized on hypothermia of OPC poisoning in view of its clinical course and complications, and health science education and training shall focus on this entity so as to recognize it and deliver required health care.

\section{Financial support and sponsorship}

Nil.

Conflicts of interest

There are no conflicts of interest.

Subramanian Senthilkumaran, Nanjundan Karthikeyan ${ }^{1}$, Ritesh G. Menezes ${ }^{2}$, Ponniah Thirumalaikolundusubramanian ${ }^{3}$

Department of Emergency and Critical Care, Be Well Hospitals, Erode, ${ }^{3}$ Department of Internal Medicine, Chennai Medical College Hospital and Research Center, Irungalur, Tiruchirappalli, Tamil Nadu, India, 'Department of Emergency Medicine, Hamad Medical Corporation, Doha, Qatar, ${ }^{2}$ Department of Pathology, Division of Forensic Medicine, College of Medicine, King Fahd Hospital of the University, University of Dammam, Dammam, Saudi Arabia

Address for correspondence: Dr. Subramanian Senthilkumaran, Department of Emergency and Critical Care Medicine, Be Well Hospitals, Erode, Tamil Nadu, India. E-mail:maniansenthil@yahoo.co.in

\section{References}

1. Munta K, Santosh P, Surath MR. Severe hypothermia causing ventricular arrhythmia in organophosphorus. Indian J Crit Care Med 2017;21:99-101.

2. Senthilkumaran S, Karthikeyan V, Jena NN, Thirumalaikolundusubramanian P. Temperature changes among organophosphate poisoned patients. J Gen Med 2016;45:345-9.

3. World Health Organisation. WHO Recommended Classification of Pesticides by Hazard and Guidelines to Classification. Geneva: WHO; 2004. 
4. Maiorana A, Roach RB Jr. Heterozygous pseudocholinesterase deficiency: A case report and review of the literature. J Oral Maxillofac Surg 2003;61:845-7.

How to cite this article: Senthilkumaran S, Karthikeyan N, Menezes RG, Thirumalaikolundusubramanian P. Hypothermia in organophosphate compound poisoning: Recognizing the big chill. Indian J Crit Care Med 2017;21:476-7.

(C) 2017 Indian Journal of Critical Care Medicine | Published by Wolters Kluwer - Medknow
This is an open access article distributed under the terms of the Creative Commons Attribution-NonCommercial-ShareAlike 3.0 License, which allows others to remix, tweak, and build upon the work non-commercially, as long as the author is credited and the new creations are licensed under the identical terms.

\begin{tabular}{|l|l|}
\hline \multicolumn{3}{|c|}{ Access this article online } \\
\hline Quick Response Code: & Website: \\
& www.ijccm.org \\
& \\
&
\end{tabular}

